\title{
Bone mineral density and explanatory factors in children and adults with juvenile dermatomyositis at long term follow-up; a cross sectional study
}

Henriette Schermacher Marstein ${ }^{1,2^{*}}$ (D, Kristin Godang ${ }^{3}$, Berit Flat $\varnothing^{4,5}$, Ivar Sjaastad ${ }^{1,6}$, Jens Bollerslev ${ }^{3,4}$ and Helga Sanner ${ }^{2,5}$

\begin{abstract}
Background: Juvenile dermatomyositis (JDM) is the most common idiopathic inflammatory myopathy in children and adolescents. Both the disease and its treatment with glucocorticoids may negatively impact bone formation. In this study we compare BMD in patients (children/adolescence and adults) with long-standing JDM with matched controls; and in patients, explore how general/disease characteristics and bone turnover markers are associated with BMD.

Methods: JDM patients $(n=59)$ were examined median 16.8y (range 6.6-27.0y) after disease onset and compared with 59 age/sex-matched controls. Dual-energy X-ray absorptiometry (DXA) was used to measure BMD of the whole body and lumbar spine (spine) in all participants, and of ultra-distal radius, forearm and total hip in participants $\geq 20 y$ only. Markers of bone turnover were analysed, and associations with outcomes explored.

Results: Reduced BMD Z-scores (<-1SD) were found in 19 and 29\% of patients and 7 and $9 \%$ of controls in whole body and spine, respectively ( $p$-values $<0.05$ ). BMD and BMD Z-scores for whole body and spine were lower in all patients and for $<20 y$ compared with their respective controls. In participants $\geq 20 y$, only BMD and BMD Z-score of forearm were lower in the patients versus controls. In patients, BMD Z-scores for whole body and/or spine were found to correlate negatively with prednisolone use at follow-up (yes/no) (age $<20 y$ ), inflammatory markers (age $\geq$ $20 y)$ and levels of interferon gamma-induced protein 10 (IP-10) (both age groups). In all patients, prednisolone use at follow-up (yes/no) and age $\geq 20 y$ were independent correlates of lower BMD Z-scores for whole body and spine, respectively.

Conclusion: In long-term JDM, children have more impairment of BMD than adults in spine and whole-body. Associations with BMD were found for both prednisolone and inflammatory markers, and a novel association was discovered with the biomarker of JDM activity, IP-10.
\end{abstract}

Keywords: Juvenile dermatomyositis, DXA, Bone mineral density, Inflammatory markers, IP-10, Prednisolone

\footnotetext{
* Correspondence: henriette.marstein@medisin.uio.no

${ }^{1}$ Institute for Experimental Medical Research and KG Jebsen Center for Cardiac Research, University of Oslo and Oslo University Hospital, Ullevål, 0027 Oslo, Norway

${ }^{2}$ Bjørknes University College, Oslo, Norway

Full list of author information is available at the end of the article
}

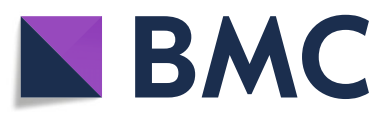

(๑) The Author(s). 2021 Open Access This article is licensed under a Creative Commons Attribution 4.0 International License, which permits use, sharing, adaptation, distribution and reproduction in any medium or format, as long as you give appropriate credit to the original author(s) and the source, provide a link to the Creative Commons licence, and indicate if changes were made. The images or other third party material in this article are included in the article's Creative Commons licence, unless indicated otherwise in a credit line to the material. If material is not included in the article's Creative Commons licence and your intended use is not permitted by statutory regulation or exceeds the permitted use, you will need to obtain permission directly from the copyright holder. To view a copy of this licence, visit http://creativecommons.org/licenses/by/4.0/. The Creative Commons Public Domain Dedication waiver (http://creativecommons.org/publicdomain/zero/1.0/) applies to the data made available in this article, unless otherwise stated in a credit line to the data. 


\section{Background}

Juvenile dermatomyositis (JDM) is the most common idiopathic inflammatory myopathy in children and adolescents. Disease activity is mitigated by immunosuppressing agents used as first-line medication; this includes prednisolone, a glucocortocoid that affects childhood bone modelling and adult bone remodelling negatively [1]. Importantly, in JDM, glucocortocoids dosage [2], treatment duration [3] and age at medication initiation [2] significantly affect bone loss. Optimal skeletal development during childhood and puberty, including bone maturation, is important in order to reach peak bone mass and prevent osteoporosis in adult life [4].

Bone mineral density (BMD) is an estimate of bone mass and is measured by dual-energy X-ray absorptiometry (DXA). However, bone formation, mineralisation and strength are also influenced by inflammatory factors, hormones and the presence of minerals, such as phosphate [5], calcium, 25-hydroxyvitamin D (25(OH)VitD) and parathyroid hormone (PTH) [6]. These markers of bone and mineral metabolism regulate bone modelling (in children) and -remodelling (in adults) by interfering with osteoblast and osteoclast activity and function [7]. Blood serum biomarkers for bone turnover are used in both the daily clinic and in biomedical research [8]. Procollagen type $1 \mathrm{~N}$-terminal propeptide (P1NP), and C-terminal telopeptide of type 1 collagen (CTX) are biomarkers of bone loss in systemic lupus erythematosus (SLE) [9], rheumatoid arthritis [10] and dermatomyositis [11]. However, P1NP and CTX in relation to bone mass and disease activity, to our knowledge, have not been studied in JDM.

Low BMD has been reported in children with JDM, whether or not they were medicated with immunosuppressing treatment [12-15]. There are concerns that such children will not reach peak bone mass, and thus will be at risk of developing osteoporotic fractures later in life $[4,12,16]$.

We and others have shown that osteoporosis (included in myositis damage index (MDI)-skeletal domain) is present in 5-9\% of JDM patients in the Nordic region after long-term follow-up $[17,18]$, and in $6 \%$ of patients globally [19].

Importantly, we are not aware of any reports evaluating DXA-based BMD in both adolescent and adult JDM patients concurrently. Thus our aim was to evaluate bone mass status and how bone remodelling factors is associated with disease outcomes and prednisolone dosages. We study both children/adolescents and adults included in our unique cohort of Norwegian JDM patients assessed after long-term follow-up compared to controls.

\section{Patients and methods}

\section{Patients and controls}

This study is part of a larger controlled, cross-sectional study in Norway. Patients were included based on a probable or definitive diagnosis of JDM according to the Bohan and Peter criteria [20]. Sixty-seven patients diagnosed between January 1970 and June 2006, fullfilled the inclusion criteria: age $<18$ years at disease onset, disease duration 24 month and age $\geq 6 y$ at inclusion. These patients were tracked through the National Population Register, and of them, 59 (95\%) participated in the overall study [21]. Age- and sex-matched controls were drawn from the same register. Data on controls, including demographics, have previously been published [21].

\section{Data collection and clinical measurements}

During a one- to two-day follow-up programme (September 2005-May 2009), study participants were examined at Oslo University Hospital (OUS). Clinical examination was performed by a single physician (HS), and DXA scans and non-fasting blood samples (serum) were taken and frozen in smaller batches at $-80^{\circ} \mathrm{C}$ for later analyses [21]. Disease activity was measured by the JDM disease activity score (DAS)(0-20) [21, 22] and cumulative organ damage by $\operatorname{MDI}(0-40)[17,22]$. MDI osteoporosis was defined as occurrences of low-energy fracture or vertebral collapse (excluding avascular necrosis). Disease duration was defined as the time from the first muscle or skin symptom associated with JDM to the follow-up examination. The patients' medication histories, including prednisolone doses, were obtained from the medical records and cumulative doses were calculated by chart review [17]. $87 \%$ of patients were treated with oral prednisolone and 15\% with intravenous methylprednisolone during disease course; at follow-up 17\% were on oral prednisolone [17] .

Participants $\geq 20$ y reported average weekly physical activity the last year by self-reporting questionnaire [23]. Due to a low number of replies from participants $<20 \mathrm{y}$ they were not included. We categorised sweat-inducing or breathless activities as number of hours of exercise: < or $\geq 2 \mathrm{~h} /$ week; and to exercise frequency: $<$ or $\geq 2$ activities/week.

In study participants $\geq 20 y$, a physical component summary scale (PCS) was measured through use of the Norwegian version of the Short Form 36 health survey (SF36 ), version 1.0 [17]. Low scores indicated poor physical status.

\section{Bone mass measurements}

Bone mineral content was determined using DXA. A narrow fan beam densitometer (GE Healthcare Lunar Prodigy, Madison, WI, USA) was used and all the scans were reanalysed in the same software version 14.10 according to a standard protocol. No hardware was changed during the study period. We analysed the anteriorposterior lumbar spine L2-L4 (spine), and whole body (WB) in study participants $<20 \mathrm{y}$ using pediatric software 
and calculated BMD (bone mineral content in $\mathrm{g} / \mathrm{cm}^{2}$ ) for these regions. For study participants $\geq 20 y$, additionally BMD for ultra-distal and distal 33\% radius (forearm), and bilateral proximal femur, dual total hip were analysed using adult software. Hence the participants were divided into two age-groups: younger than 20 years $(<20 y)$, and older or equal to 20 years $(\geq 20 y)$. BMD Zscores were estimated by comparison with the Lunar reference database incorporated in the software and provided by the manufacturer. The database includes BMD data from healthy subjects in the general population of the United States, which has been validated as applicable for clinical use in the adult [24] as well as the pediatric Norwegian population [25]. Z-scores <-1SD below the age-specific mean for healthy individuals were defined as reduced $[12,26,27]$.

\section{Laboratory analyses}

The biomarkers of bone resorption (CTX) and formation (P1NP) were measured by electroluminescence technology using a Cobas e601 (Roche). The bone metabolism marker $25(\mathrm{OH})$ VitD was measured using liquid chromatography/tandem mass spectrometry. Insufficient amounts of $25(\mathrm{OH})$ VitD were defined as levels $\leq 20 \mathrm{nmol} / \mathrm{l}$ according to expert consensus [28] and low as $\leq 37 \mathrm{nmol} / \mathrm{l}$ (corresponding to the lower level of the reference value for the general population in Norway). All analyses were performed at the Hormone Laboratory, Department of Medical Biochemistry, OUS, Oslo in 2019. Levels of IP-10 (CXCL10), a known marker of disease activity in JDM [29], was measured as part of a 27-plex cytokine panel (Bio-Plex immunoassay systems, \#m500kcaf0y, Bio-Rad, Hercules, CA), based on xMAP technology (Luminex, Austin, TX) in 2012. All samples were handled and analysed according to manufacturer protocol without freeze/thaw cycles. Measurements of erythrocyte sedimentation rate (ESR) and serum levels of high-sensitivity C-reactive protein (hsCRP), and of the bone minerals albumin, phosphate, PTH, alkaline phosphatase and ionised calcium, were performed consecutively at the Department of Medical Biochemistry, OUS or at local hospitals when appropriate. All analyses were performed in non-fasting serum samples according to standard protocols for the analytical methods. We are aware that non-fasting samples contribute to some uncertainty in the absolute measures reported, as feeding affects concentrations of most biological serum factors.

\section{Statistics}

SPSS version 27 (SPSS, Chicago, IL) was used for statistical analyses. Paired samples t-tests, Mann-Whitney U tests, Wilcoxon signed rank and chi-square tests were used to compare patient characteristics, BMD, BMD Z- scores and bone-turnover markers to matched controls. To identify explanatory risk factors for impaired bone density, associations between bone density measures (BMD and BMD Z-scores), markers of bone and mineral metabolism and disease activity measures at follow-up, were analysed using Spearman's correlation coefficient (rsp) for continuous and Pearson's correlation coefficient for categorical variables (point bi-serial correlation). Subsequent multivariate linear regression analysis was used in order to identify correlates, with forward selection of possible correlates. Due to the relatively low n, limitations for numbers of variables into the regression analysis forced us to select possible explanatory variables (e.g only one inflammatory marker / prednisone variable). Explanatory variables were included in the models if they showed an association with the outcome variable in univariate analyses or were known from the literature to be associated with the outcomes $(p$-value $<0.1)$. Due to the hypothesis-generating nature of our study, data was not corrected for multiple comparisons.

\section{Results \\ Characteristics of JDM patients}

In total 28/59 (47.5\%) of both patients and controls were under the age of 20; 20 girls and eight boys (Table 1). Median disease duration was $16.8 \mathrm{y}$ (Table 1); 6.5y (IQR $4.9-8.7 y$ ) and 26.3y (IQR 18.9-31.0y) for patients <20y and $>20 y$ respectively. There was no significant difference in body mass index between patients and controls; however, patients were on average $2.4 \mathrm{~cm}$ shorter than controls ( $p$-value $=0.05$ ). Time from diagnosis to immunosuppressive medication was comparable for both age groups. The occurrence of fractures during life was comparable between patients and controls (Table 1). As previously described, the SF-36 physical component score chart revealed a significantly reduced score for physical activity among the patients compared with controls [23]. The SF-36 scores were 4.3 units lower in patients $\geq 20 y$ compared with controls. There were no significant differences in neither hours spent nor frequency of physical activity per week in patients vs. controls $\geq 20 \mathrm{y}$.

\section{Bone mass measures in study participants}

BMD and BMD Z-scores for WB and spine in all patients tended to be lower than in controls (Table 2). Patients $<20 \mathrm{y}$ had lower BMD WB and spine $(\Delta=0.04 \mathrm{~g} /$ $\mathrm{cm}^{2}$ and $0.08 \mathrm{~g} / \mathrm{cm}^{2}, p$-values $=0.02$ and 0.04$)$ and BMD Z-scores for WB and spine $\left(\Delta=0.04 \mathrm{~g} / \mathrm{cm}^{2}\right.$ and $0.08 \mathrm{~g} /$ $\mathrm{cm}^{2}, p$-values $=0.02$ and 0.04) compared with controls $<$ $20 \mathrm{y}$. However, these differences in BMD and BMD Zscores for WB and spine were not found between patients and controls $\geq 20 \mathrm{y}$. For DXA variables that were only assessed in study participants $\geq 20 \mathrm{y}$, patients had 
Table 1 Characteristics and disease variables in JDM patients and controls

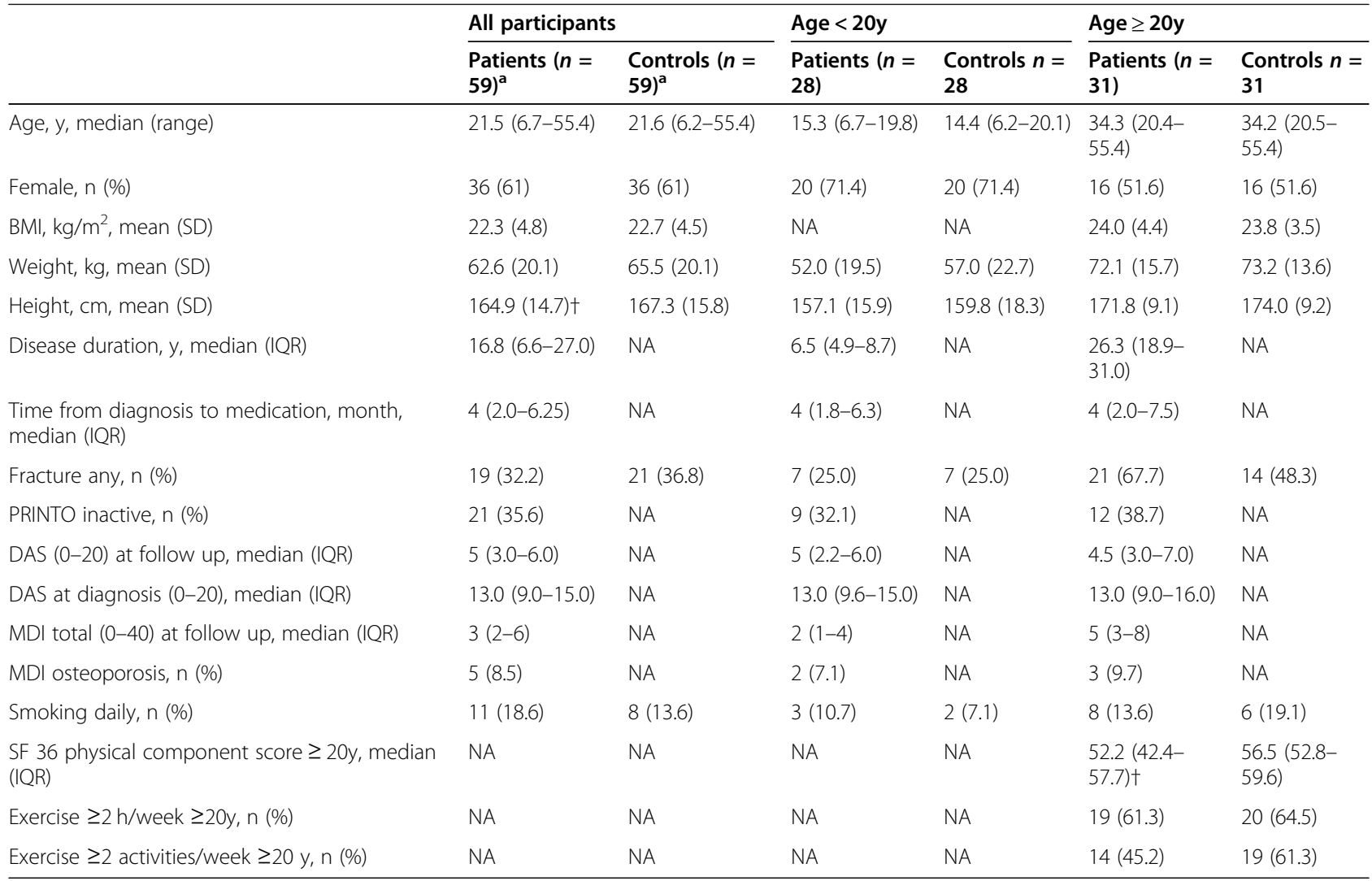

$B M I$ body mass index, DAS disease activity score, MDI myositis damage index, RINTO paediatric rheumatology international trials organisation, NA not applicable, ${ }^{a}$ In each age group $n=59$ otherwise stated as $n \geq 20 y=31$ and $n<20 y=28$ ). $t p<0.05$. $p$-values when comparing patients and controls using paired sample ( 2 tailed) or chi-square tests when appropriate

lower BMD and BMD Z-scores for the forearm compared with controls $\left(\Delta=0.06 \mathrm{~g} / \mathrm{cm}^{2}\right.$ and 0.71 both $p$ values $=0.01$ ), whereas no significant differences were found between groups for ultra-distal radius and hip. In study participants $\geq 20 \mathrm{y}$, there were no differences in $\mathrm{T}$ scores for any of the acquisition regions.

\section{Occurrence of reduced BMD Z-scores in study participants}

$12 \%$ more patient had reduced BMD Z-scores for WB and $20 \%$ more had reduced BMD Z-scores for spine compared to controls (both $p$-values <0.01) (Fig. 1a). Also, in the participants $<20 \mathrm{y}, 26 \%$ more patients than controls had reduced $Z$-values for the spine (Fig. 1b). In the participants $\geq 20 y$, reduced Z-scores in the forearm were found in $26 \%$ more patients than in controls; for the other regions examined, there were non-significant trends of more frequent reduced BMD Z-scores for spine and total hip in patients vs. controls (Fig. 1c).

\section{Prednisolone use in patients}

At follow-up, 10 patients (16.9\%) used prednisolone; of those, seven were $<20$ y (Table 3 ). Two patients $<20 y$ and six $\geq 20 y$ had not been medicated with prednisolone during the disease course. Not surprisingly, patients $\geq 20 y$ had used prednisolone for twice as long as patients $<20 \mathrm{y}$, and cumulatively, their doses were 1.5 times greater than the doses given to patients $<20 \mathrm{y}$ (both $p$ values $=0.02$ ). However, months from last prednisolone dose to FU were 3.4 times longer in patients $\geq 20 \mathrm{y}$ compared to patients $<20 \mathrm{y}$. Cumulative prednisolone doses after 6 months and 2 years were comparable between patients $<20 \mathrm{y}$ and $\geq 20 \mathrm{y}$. However, when comparing cumulative prednisolone doses at 6.5y, (which was the mean time of disease duration for patients $<20 y$ ), patients $\geq 20 y$ were medicated with prednisolone doses that on average were 1.5 times as high as those given to patients $<20 y$.

\section{Serum markers of bone and mineral metabolism in study participants}

In all patients, reduced levels of 25(OH)VitD $(\Delta=11$ $\mathrm{nmol} / \mathrm{L})$ and higher levels of phosphate $(\Delta=0.10 \mathrm{nmol} /$ L) were found compared with controls ( $p$-values $=0.001$ and 0.005) (Table 4). Also, total calcium and albumin levels were lower in patients than in controls $(\Delta=0.04$ $\mathrm{nmol} / \mathrm{L}$ and $1.5 \mathrm{nmol} / \mathrm{L}, \quad p$-values $=0.004$ and 0.002 ); 
Table 2 BMD and Z scores in JDM patients and controls in total, $<20 \mathrm{y}$ and $\geq 20 \mathrm{y}$

\begin{tabular}{|c|c|c|c|c|c|}
\hline Variable & Patients $(n=59)$ & Controls $(n=59)$ & $\begin{array}{l}\text { Patients <20y }(n=28) \\
\geq 20 y(n=31)\end{array}$ & $\begin{array}{l}\text { Controls <20y }(n=28) \\
\geq 20 y(n=30-31)\end{array}$ & $p$-values \\
\hline \multicolumn{6}{|l|}{ BMD, $\mathrm{g} / \mathrm{cm}^{2}$} \\
\hline Whole body & $1.10(0.15)$ & $1.13(0.14)$ & & & 0.05 \\
\hline Age $<20 y$ & & & $1.01(0.13)$ & $1.06(0.16)$ & 0.02 \\
\hline Age $\geq 20 y$ & & & $1.18(0.10)$ & $1.19(0.08)$ & 0.71 \\
\hline Lumbar spine, L2-L4 & $1.12(0.23)$ & $1.17(0.22)$ & & & 0.07 \\
\hline Age $<20 y$ & & & $0.99(0.21)$ & $1.07(0.27)$ & 0.04 \\
\hline Age $\geq 20 y$ & & & $1.24(0.18)$ & $1.26(0.11)$ & 0.52 \\
\hline \multicolumn{6}{|l|}{ Total hip } \\
\hline Age $\geq 20 y$ & & & $1.00(0.18)$ & $1.05(0.14)$ & 0.10 \\
\hline \multicolumn{6}{|l|}{ Ultra distal radius } \\
\hline Age $\geq 20 y$ & & & $0.48(0.08)$ & $0.5(0.08)$ & 0.13 \\
\hline \multicolumn{6}{|l|}{ Forearm } \\
\hline Age $\geq 20 y$ & & & $0.87(0.09)$ & $0.93(0.11)$ & 0.01 \\
\hline \multicolumn{6}{|l|}{ Z-score } \\
\hline Whole body & $-0.07(1.08)$ & $0.27(0.90)$ & & & 0.06 \\
\hline Age $<20 y$ & & & $-0.39(0.99)$ & $0.28(1.01)$ & 0.01 \\
\hline Age $\geq 20 y$ & & & $0.21(1.10)$ & $0.26(0.71)$ & 0.83 \\
\hline Lumbar spine, L2-L4 & $-0.16(1.2)$ & $0.4(1.02)$ & & & 0.07 \\
\hline Age $<20 y$ & & & $-0.39(1.01)$ & $0.25(1.21)$ & 0.04 \\
\hline Age $\geq 20 y$ & & & $0.06(1.34)$ & $0.24(0.84)$ & 0.56 \\
\hline \multicolumn{6}{|l|}{ Total hip } \\
\hline Age $\geq 20 y$ & & & $-0.32(1.35)$ & $0.14(0.99)$ & 0.10 \\
\hline \multicolumn{6}{|l|}{ Ultra distal radius } \\
\hline Age $\geq 20 y$ & & & $-0.42(1.36)$ & $0.16(1.33)$ & 0.13 \\
\hline \multicolumn{6}{|l|}{ Forearm } \\
\hline Age $\geq 20 y$ & & & $-0.76(1.03)$ & $-0.05(0.87)$ & 0.01 \\
\hline \multicolumn{6}{|l|}{ T-score } \\
\hline \multicolumn{6}{|l|}{$\geq 20 y$} \\
\hline Whole body & NA & NA & $0.16(1.25)$ & $0.29(0.82)$ & 0.81 \\
\hline Lumbar spine, L2-L4 & NA & NA & $0.00(1.44)$ & $0.25(0.92)$ & 0.09 \\
\hline Total hip & NA & NA & $0.42(1.41)$ & $0.07(1.04)$ & 0.07 \\
\hline Ultra distal radius & NA & NA & $-0.43(1.35)$ & $0.14(1.35)$ & 0.48 \\
\hline Forearm & NA & NA & $-0.77(1.00)$ & $-0.07(0.87)$ & 0.38 \\
\hline
\end{tabular}

$B M D$ bone mineral density, $y$ years. Values for total hip, ultra distal and forearm are not applicable for age $<20 y$. Values are mean (SD). $p$-values when comparing patients and controls using paired samples t-test

however, insufficient levels of $25(\mathrm{OH}) \mathrm{VitD}$ and ionised calcium were comparable between patients and controls.

In study participants <20y, phosphate levels were higher in patients compared with the respective controls $(\Delta=0.12 \mathrm{nmol} / \mathrm{L}, p$-value $=0.005)$. There were no significant differences in levels of any bone remodelling factors including CTX, P1NP and PTH between patients and controls nor between the age groups $</ \geq 20$ y (Table 4 ).

\section{Associations between BMD Z-scores and prednisolone use and dosage in patients}

For all patients, we found a negative correlation between prednisolone use at follow-up (yes/no) and the Z-score of spine (Table 5). In patients $<20 y$, all prednisolone variables (use at follow-up, use in months and cumulative dosage) correlated negatively with the BMD Z-score for spine (Table 5). In patients $\geq 20 y$, 

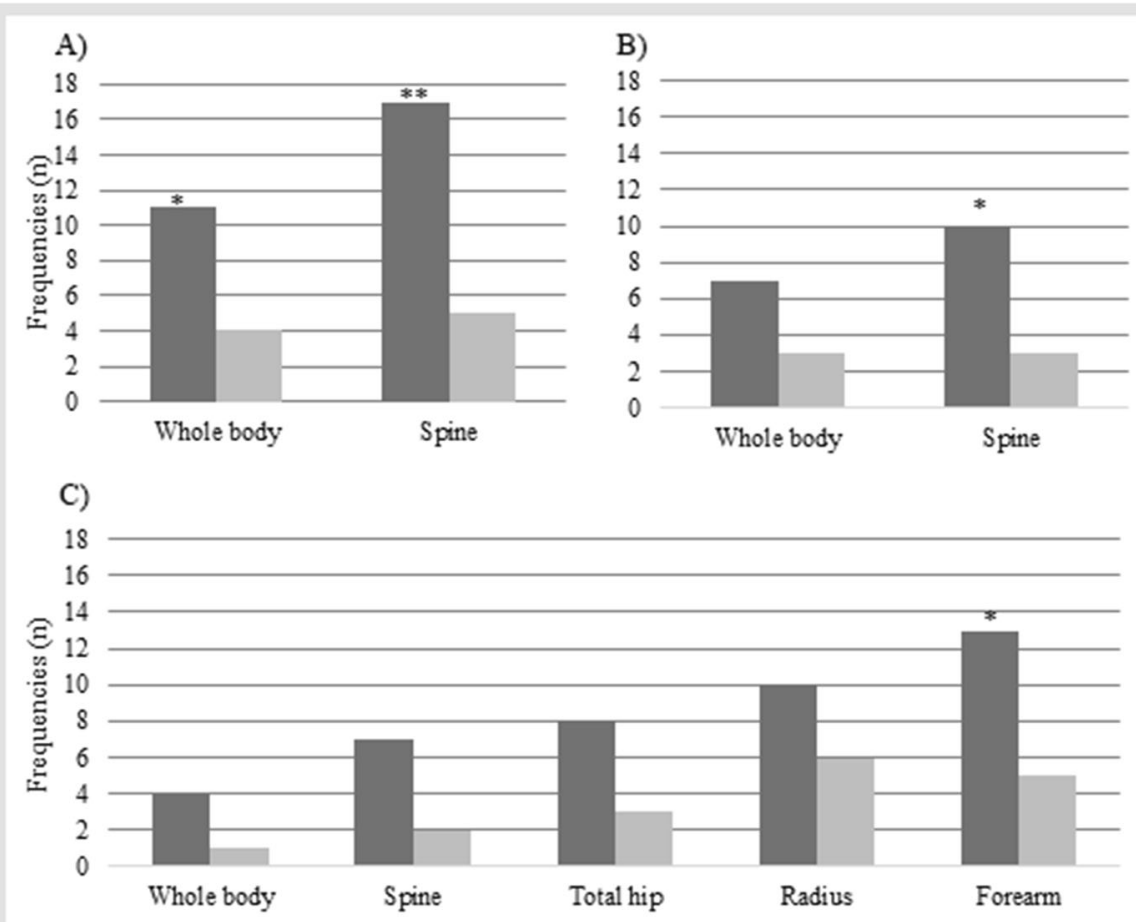

Fig. 1 Frequencies of reduced BMD Z-scores in patients compared to controls. (a) shows data of WB and lumbar spine in all study participants, (b) shows data of WB and lumbar spine in study participants <20y and (c) shows data on WB, lumbar spine, total hip, ultra-distal radius and forearm in study participants in study participants $\geq 20 y$. WB: WB, LS: lumbar spine, TH: Total hip, UD: Ultra distal radius, FA: Forearm. ${ }^{*}<0.05$ and ${ }^{* *} p<0.01$

there were positive correlations between prednisolone use in months and the Z-score for WB (Table 5).

\section{Associations between levels of bone remodelling factors and BMD Z-score in study participants}

In all patients, we found levels of PTH and IP-10 to correlate negatively with the BMD Z-score in $\mathrm{WB}(p$-values $=0.01$ and
0.03) (Table 5). In patients $<20 y$ levels of IP-10 correlated negatively with the BMD Z-score for spine. We also found a positive correlation between levels of hsCRP and the BMD Z-score in WB in controls $<20 y$. In patients $\geq 20 y$ : levels of IP-10 were negatively associated with the BMD Z-score for WB. Further, the ESR and hsCRP were negatively associated with the BMD Z-score for spine in patients $\geq 20 y$ (Table 5).

Table 3 Medication in JDM patients total, <20y and $\geq 20 y$

\begin{tabular}{|c|c|c|c|c|}
\hline Medication & Patients $(n=59)$ & Patients < 20 y $(n=28)$ & Patients $\geq 20$ y $(n=31)$ & $p$-values \\
\hline Prednisolone or DMARD at FU, $\mathrm{n}$ & $17(28.8)$ & $13(46.4)$ & $4(12.9)$ & 0.004 \\
\hline Prednisolone at FU (yes/no), n & $10(16.9)$ & $7(12.5)$ & $3(4.8)$ & 0.13 \\
\hline Methotrexat at FU, n & $10(8.5)$ & $9(16.1)$ & $1(1.6)$ & 0.01 \\
\hline Prednisolone during disease course, $\mathrm{n}$ & $51(86.4)$ & $26(92.9)$ & $25(80.6)$ & 0.17 \\
\hline Methotrexat during disease course, $\mathrm{n}$ & $30(50.8)$ & $18(64.3)$ & $12(38.7)$ & 0.05 \\
\hline Prednisolone medication time, months & $31(14.0-57.0)$ & $24.5(13.3-35.0)$ & $48.0(16.0-85.0)$ & 0.05 \\
\hline Cumulative prednisolone total, $\mathrm{g}$ & $7.90(30.00-79.23)$ & $6.14(0.00-16.23)$ & $9.68(0.00-79.23)$ & 0.03 \\
\hline Cumulative prednisolone $6 \mathrm{~m}$ after diagnosis ${ }^{\mathrm{a}}, \mathrm{g}(n=58 / 28 / 31)$ & $2.76(0.00-6.65)$ & $2.89(0.00-6.38)$ & $2.61(0.00-6.65)$ & 0.60 \\
\hline Cumulative prednisolone 2 y after diagnosis, $\mathrm{g}$ & $4.81(0.00-0-16.50)$ & $4.26(0.00-9.80)$ & $6.75(0.00-16.49)$ & 0.19 \\
\hline Cumulative prednisolone 6.5 y after diagnosis, $\mathrm{g}$ & $7.35(0.00-28.39)$ & $6.14(0.00-12.64)$ & $9.43(0.00-28.40)$ & 0.18 \\
\hline Time from last prednisolone dose to FU, months & $67.0(0-162.0)$ & $42.7(0-67.8)$ & $145.0(0-253.0)$ & 0.002 \\
\hline
\end{tabular}

FU follow up, ${ }^{a} n=56$, values are $\mathrm{n}(\%)$ and median (range). $p$-values when comparing JDM <20y and JDM $\geq 20 y$ 
Table 4 Bone remodeling factors in JDM patients and controls

\begin{tabular}{|c|c|c|c|}
\hline & Patients $(n=55-58)$ & Controls $(n=55-58)$ & $p$-values \\
\hline CTX, ug/l & $0.51(0.34-0.97)$ & $0.46(0.30-0.96)$ & 0.34 \\
\hline P1NP, ug/l & $73.0(46.8-318.0)$ & $75.0(52.8-352.0)$ & 0.63 \\
\hline 25-OH-VitD, nmol/l & $54.0(37.0-65.0)$ & $65.0(45.0-83.0)$ & 0.001 \\
\hline Low 25(OH)VitD $(<37 \mathrm{nmol} / \mathrm{l}), \mathrm{n}$ & $13(22.4)$ & $4(6.9)$ & 0.08 \\
\hline Insufficient 25(OH)VitD (<20nmo/l), n & $3(5.5)$ & $0(0)$ & 0.02 \\
\hline Calsium, nmol/l & $2.29(2.24-2.33)$ & $2.33(2.29-2.39)$ & 0.001 \\
\hline iCalsium, nmol/l & $1.25(0.04)$ & $1.25(0.03)$ & 0.83 \\
\hline Albumin, $g / l$ & $44.5(2.3)$ & $45.9(2.3)$ & 0.002 \\
\hline Alkaline phosphatase, U/I & $71.0(56.0-147.3)$ & $72.00(55.0-150.8)$ & 0.97 \\
\hline Phosphate, nmol/l & $1.23(0.25)$ & $1.13(0.21)$ & 0.005 \\
\hline PTH, pmol/l & $3.52(1.19)$ & $3.53(1.27)$ & 0.95 \\
\hline $\mathrm{E}-\mathrm{SR}, \mathrm{mm} / \mathrm{h}$ & $5.0(3.0-9.0)$ & $4.0(3.0-8.0)$ & 0.06 \\
\hline hsCRP, mg/l & $0.98(0.28-2.6)$ & $0.59(0.23-1.27)$ & 0.12 \\
\hline IP-10, pg/ml & $1009(911-1581)$ & $969(751-1187)$ & 0.04 \\
\hline Age $<20$ y & $(n=25-28)$ & $(n=25-28)$ & \\
\hline CTX, ug/l & $0.94(0.55-1.39)$ & $0.97(0.49) 1.22$ & 0.73 \\
\hline P1NP, ug/l & $326.0(95.0-560.78)$ & $397.0(95.0-608.7)$ & 0.77 \\
\hline 25-OH-VitD, nmol/l & $55.4(19.0)$ & $66.2(24.4)$ & 0.11 \\
\hline Low 25(OH)VitD $(<37 \mathrm{nmol} / \mathrm{l}), \mathrm{n}$ & $6(21.4)$ & $2(7.1)$ & 0.31 \\
\hline Insufficient 25-OH-VitD (<20 nmol/l), n & $1(3.7)$ & $0(0)$ & 0.13 \\
\hline Calsium, nmol/l & $2.3(0.2)$ & $2.3(0.01)$ & 0.18 \\
\hline iCalsium, nmol/l & $1.26(0.03)$ & $1.26(0.03)$ & 0.75 \\
\hline Albumin, $g / l$ & $44.8(2.1)$ & $45.8(2.1)$ & 0.10 \\
\hline Alkaline phosphatase, U/l & $149.5(74.3-226.8)$ & 152.5 (76.5-194.8) & 0.60 \\
\hline Phosphate, nmol// & $1.35(0.23)$ & $1.23(0.23)$ & 0.005 \\
\hline PTH, pmol/l & $3.55(1.23)$ & $3.32(1.28)$ & 0.50 \\
\hline $\mathrm{E}-\mathrm{SR}, \mathrm{mm} / \mathrm{h}$ & $4.50(3.00-8.25)$ & $4.50(3.00-10.50)$ & 0.44 \\
\hline hsCRP, mg/l & $0.40(0.24-2.44)$ & $0.35(0.19-1.27)$ & 0.43 \\
\hline IP-10, pg/ml & $982(855-1479)$ & $889(732-1125)$ & 0.14 \\
\hline Age $\geq 20 y$ & $(n=28-30)$ & $(n=28-30)$ & \\
\hline CTX, ug/l & $0.40(0.24-0.49)$ & $0.32(0.23-0.41)$ & 0.16 \\
\hline P1NP, ug/l & $55.0(41.8-59.0)$ & $59.0(42.8-68.0)$ & 0.23 \\
\hline 25(OH)VitD, nmol/l & $47.3(17.2)$ & $65.3(21.4)$ & 0.001 \\
\hline Low 25(OH)VitD $(<0.37 \mathrm{nmol} / \mathrm{l}), \mathrm{n}$ & $7(23.3)$ & $2(6.7)$ & 0.15 \\
\hline Insufficient 25(OH)VitD (<20 nmol/l), n & $2(7.1)$ & $0(0)$ & 0.07 \\
\hline Calsium, nmol/l & $2.25(0.11)$ & $2.34(0.09)$ & 0.002 \\
\hline iCalsium, nmol/l & $1.24(0.04)$ & $1.24(0.03)$ & 0.62 \\
\hline Albumin, g/l & $44.3(2.5)$ & $46.0(2.5)$ & 0.004 \\
\hline Alkaline phosphatase, U/I & $61.0(49.0-73.3)$ & $59.0(50.0-70.5)$ & 0.66 \\
\hline Phosphate,nmol// & $1.10(0.22)$ & $1.03(0.17)$ & 0.15 \\
\hline PTH, pmol/l & $3.5(1.17)$ & $3.73(1.44)$ & 0.48 \\
\hline $\mathrm{E}-\mathrm{SR}, \mathrm{mm} / \mathrm{h}$ & $7.0(3.0-8.5)$ & $4.0(3.0-8.0)$ & 0.08 \\
\hline hsCRP, mg/l & $1.07(0.43-3.5)$ & $0.63(0.33-1.27)$ & 0.15 \\
\hline IP-10, pg/ml & $1066(940-1593)$ & $1041(764-1201)$ & 0.14 \\
\hline
\end{tabular}


CTX C-terminal collagen crosslinks, P1NP pro-collagen type $1 \mathrm{~N}$-terminal pro-peptide, 25-OH-VitD 25-hydroxyvitamin D, insufficient 25(-OH)-VitD <20 nmol/l; Low $25(\mathrm{OH})$ VitD, $n<37 \mathrm{nmol} / \mathrm{l}$; iCalsium: ionized calcium, $P T H$ parathyroid hormone, E-SR erythrocyte sedimentation rate, $h s C R P$ high sensitive $C$-reactive protein, IP-10 Interferon gamma-induced protein 10. Values are mean (SD) or median (IQR). P-values when comparing patients and controls using independent samples t-test or chi-square for nonparametric values

\section{Correlates of BMD Z-scores in patients}

In multivariate linear regression models, the BMD Zscores for the WB and spine were used as dependent variables. The age at diagnosis, age $\geq 20 \mathrm{y}$ at follow-up, prednisolone use at follow-up (yes/no), and low levels of 25(OH)VitD, IP-10 and hsCRP were treated as independent variables. We found age $\geq 20 y$ to be correlated to the BMD Z-score in WB ( $p$-value $=0.05)$, and prednisolone use at follow-up (yes/no) was associated with the BMD Z-score in spine ( $p$-value $=0.007)$ (Supplementary Table 1).

\section{Discussion}

Data on bone health in JDM after long-term follow-up is lacking. We found higher prevalence of reduced BMD Z-scores in both WB and spine in patients than in controls and bone density was differently affected in patients $<20 y$ vs. $\geq 20 y$. In patients $<20 y$, bone density of WB and spine were lower compared with controls and was negatively associated with prednisolone dose. In patients $\geq 20 y$, only bone density in the forearm was lower compared with controls and BMD Z-score for spine correlated negatively with inflammatory parameters. The biomarker of JDM activity, IP-10 was associated with lower BMD Z-scores in both age groups. In all patients, prednisolone use at follow-up (yes/no) and age $\geq 20 \mathrm{y}$ were independent correlates of BMD Z-scores in WB and spine, respectively.
Our findings of more frequent reduced BMD Z-scores for WB and spine in all patients vs controls are in line with a study from our centre, which examined children and adults with juvenile-onset SLE (jSLE) [26]. By including both children and adults, we had the unique opportunity to evaluate whether and how BMD was affected early and late in JDM disease course. Due to differences in DXA acquisition regions and expected differences in bone mineralisation status between children and adults [30], we discuss the findings of patients $<20 y$ and $\geq 20 y$ separately.

In patients $<20 y, B M D$ and BMD Z-scores in both WB and spine were lower compared with respective controls. Similar results have been found in both untreated JDM [13] and after 0.2-8.3y [12, 13]. Our finding of reduced BMD Z-scores of spine in $36 \%$ of our patients $<20 y$ (after median $6.5 y$ disease duration) is comparable with frequencies found in children with chronic rheumatic diseases (including JDM) (25-70\%) after variable disease durations [2, 14, 16, 26, 27]. Patients $\geq 20 y$ had lower BMD and BMD Z-scores of the forearm than controls, and $42 \%$ of these patients had reduced BMD Z-scores. This is line with other studies of adult patients with juvenile-onset autoimmune diseases including juvenile idiopathic arthritis (50\%) [31] and jSLE $(\approx 30 \%)$ [26]. Possible explanatory factors for reduced bone density in our patients are discussed below.

Table 5 Associations between BDM and BMD Z-score and: prednisolone and bone remodeling factors in JDM patients and controls, younger and older than 20 years

\begin{tabular}{|c|c|c|c|c|c|c|}
\hline & $\begin{array}{l}\text { Patients } \\
\text { Total }\end{array}$ & $\begin{array}{l}\text { Controls } \\
\text { Total }\end{array}$ & $\begin{array}{l}\text { Patients } \\
\text { Age }<20 y\end{array}$ & $\begin{array}{l}\text { Controls } \\
\text { Age }<20 y\end{array}$ & $\begin{array}{l}\text { Patients } \\
\text { Age } \geq 20 y\end{array}$ & $\begin{array}{l}\text { Controls } \\
\text { Age } \geq 20 y\end{array}$ \\
\hline \multicolumn{7}{|l|}{ BMD Z-score, Whole body } \\
\hline Prednisolone use at FU & -0.26 & NA & -0.26 & NA & -0.20 & NA \\
\hline Prednisolone use (month) & 0.18 & NA & -0.36 & NA & $0.43^{*}$ & NA \\
\hline PTH & $-0.30^{*}$ & 0.01 & -0.29 & 0.15 & -0.33 & -0.12 \\
\hline IP-10 & $-0.34^{*}$ & 0.16 & -0.38 & 0.14 & $-0.38^{*}$ & 0.25 \\
\hline hsCRP & -0.15 & 0.234 & -0.21 & $0.54^{* *}$ & -0.22 & 0.07 \\
\hline \multicolumn{7}{|l|}{ BMD Z-score, Lumbar spine } \\
\hline Prednisolone use at FU & $-0.41^{*}$ & NA & $-0.45^{*}$ & NA & -0.34 & NA \\
\hline Prednisolone use (month) & 0.01 & NA & $-0.40^{*}$ & NA & 0.18 & NA \\
\hline Cumulative prednisolone & 0.00 & NA & $-0.48^{*}$ & NA & 0.15 & NA \\
\hline IP-10 & -0.21 & 0.20 & $-0.42^{*}$ & 0.10 & -0.19 & 0.19 \\
\hline hsCRP & -0.24 & 0.19 & -0.19 & $0.39^{*}$ & $-0.40^{*}$ & 0.03 \\
\hline
\end{tabular}

FU follow up, 25-OH-VitD 25-hydroxyvitamin D, IP-10 interferon gamma-induced protein 10, hsCRP high sensitive C-reactive protein, $N A$ not applicable All values are Spearmans correlation or point bi-serial correlations when appropriate, ${ }^{*} p<0.05,{ }^{* *} p<0$ 
Prednisolone (months used, use at follow-up and cumulative doses) was associated with lower bone mass in the spine, especially in patients $<20 y$. It is well established that prednisolone influences bone modelling negatively in children [1], especially of the spine [32]. However, studies addressing how prednisolone treatment in JDM affects BMD are conflicting as some find negative correlations between corticosteroid treatment and bone density $[2,15]$ while others do not [14] . In addition, the effects of prednisolone are likely to be duration- and dose-dependent [1].

Since the $\geq 20 y$-group had fewer pathological BMD findings, one could speculate that they had received less prednisolone than the $<20 y$-group. However, after 6.5 years (which is median disease duration for patients < $20 y$ ), patients $\geq 20 y$ had 1.5 times higher cumulative prednisolone dose (borderline significance) than those < $20 y$. Also, age $\geq 20 y$ was identified as an independent correlate of low BMD Z-scores for WB. The association between higher BMD Z-scores for WB and prednisolone use in months in patients $\geq 20 \mathrm{y}$ is surprising. However, patients $\geq 20$ used prednisolone $>3$ times longer during disease course (not significant) and had longer time off prednisolone compared to patients $<20 y$. It might be that bone density may improve and bone health may reconstitute after corticosteroid discontinuation [33].

Here for the first time we report levels of CTX and P1NP in JDM patients; both were comparable between patients and controls. It is known that glucocorticoid treatment negatively affects both CTX and P1NP [11, 34]. Hence, in our patients normal CTX and P1NP levels might be mirroring differences in treatment plans, and the aforementioned reconstituted bone health, rather than an effect from prednisolone.

The biomarker of JDM, IP-10 [29], correlated negatively with BMD Z-scores in both age groups. Downregulation of IP-10 has been found to decrease osteoclast differentiation and thereby prevent bone degradation [35]. However, to our knowledge, the effect of IP-10 upon BMD has not been examined in other autoimmune inflammatory diseases. Interestingly, studying the same cohort, we have previously found an association between higher IP-10 and pulmonary involvement [36], which indicates a multiorgan role of this cytokine in JDM that should be studied further. Additionally, the inflammatory markers ESR and hsCRP were associated with low BMD Z-scores of spine in patients $\geq 20 y$ [37], which is in line with findings in both children and adults with autoimmune rheumatic diseases $[12,16,31]$. Also, levels of CRP might predict impaired bone density in general [38].

All patients and patients $\geq 20 y$ had lower vitamin $D$ levels than the controls. Low vitamin D contributes to a lower BMD by increasing bone remodelling [39]. Data on vitamin D levels in IIM including JDM is conflicting [15, 40, 41]. Vitamin D levels might be reduced in JDM patients [38, 39] due to patients' photosensitivity [40], involuntarily reduction in sunexposure and insufficient dietary vitamin D. Regrettably, we have no data on dietary vitamin $\mathrm{D}$ intake.

Strengths of our study include that $95 \%$ of all identified and tracked JDM patients participated in the study; our results are thus less biased toward serious cases compared to other outcome studies [42]. Since our ageand sex-matched controls were randomly drawn from the Norwegian registry, we believe they reflect the general population. Also, the external validity of our results is supported by the finding of MDI assessed osteoporosis in $5(8.5 \%)$ patients [17], which is in line with other studies $[18,19]$. There are some limitations to our study other than those already discussed: we did not adjust for multiple testing due to the hypothesis generating nature of our study. We used $<20 />20 y$ as age-cut-off, which does not necessarily correlate with sexual maturation and developmental stages of importance to bone maturation. Tanner stage was only reported from a limited number of patients $<20 \mathrm{y}$ and hence not included in the study. Also, volumetric BMD and skeletal age were not assessed, leaving us unable to discuss these measures as explanatory factors. We are also limited by the lack of prospective data on disease activity.

\section{Conclusion}

After long-term follow-up, bone density in JDM children and adults are differently affected. Compared with controls, both children and adolescents with JDM show reductions in BMD and BMD Z-scores in both WB and spine. The shown association between impaired BMD Z-scores and prednisolone use at follow-up (yes/no), age $>20 y$ and higher levels of inflammatory markers confirms already established associations, while the association with the JDM biomarker IP-10 found in adult patients is novel and should be studied further.

\begin{abstract}
Abbreviations
JDM: Juvenile dermatomyositis; BMD: Bone mineral density; DXA: Dualenergy X-ray absorptiometry; 25(OH)VitD: 25-hydroxyvitamin D;

PTH: parathyroid hormone; P1NP: Procollagen type $1 \mathrm{~N}$-terminal propeptide; CTX: C-terminal telopeptide of type 1 collagen; SLE: Systemic lupus erythematosus; MDI: Myositis damage index; OUS: Oslo university hospital; DAS: Disease activity score; PCS: physical component summary scale; SF36: Short Form 36 health survey; WB: Whole body; IP-10: Interferon gammainduced protein 10; ESR: Erythrocyte sedimentation rate; hsCRP: highsensitivity C-reactive protein; jSLE: Juvenile-onset SLE
\end{abstract}

\section{Supplementary Information}

The online version contains supplementary material available at https://doi. org/10.1186/s12969-021-00543-Z

Additional file 1: Supplementary Table 1. Correlates of BMD Z-score whole body and lumbar spine in patients. 


\section{Acknowledgements}

The authors would like to thank Anita Tollisen for help with patient inclusion, Ellen Nordal and Marite Rygg for patient recruitment, Maria Vistnes and Thomas Schwartz for help with cytokine analysis, Gunhild Lien with help with the physical activity questionnaire and Kari Julien for vitamin D and bone turnover marker analyses.

\section{Authors' contributions}

HSM: Analysis and interpretation of data, and manuscript preparation. KG: Design, Data acquisition and interpretation, and revision of manuscript. BF: Conception of study, interpretation of data, and revision of manuscript. IS: Conception of study, interpretation of data and revision of manuscript. JB: Design of study, interpretation of data, and revision of manuscript. HS: Conception and design of the study, interpretation of data, and manuscript preparation. All authors have: have agreed both to be personally accountable for the author's own contributions and to ensure that questions related to the accuracy or integrity of any part of the work, even ones in which the author was not personally involved, are appropriately investigated, resolved, and the resolution documented in the literature. All authors have approved the submitted manuscript.

\section{Funding}

The study was supported by the Anders Jahres Fund for promotion of science and the Olav Raagholt and Gerd Meidel Raagholt Research Foundation.

\section{Availability of data and materials}

Due to ethical concerns, supporting data cannot be made openly available. The datasets generated during and/or analyzed during the current study are not publicly available due to safeguarding by the EU General Data Protection Regulation and Norwegian law.

\section{Declarations}

\section{Ethics approval and consent to participate}

According to the declaration of Helsinki, written informed consent was obtained from all patients - parents if the patients were aged $<16 y$ - and controls. The study was approved by the Regional Ethics Committee of Medical Research (S-05144).

\section{Consent for publication}

Not applicable.

\section{Competing interests}

The authors declare that they have no competing interests.

\section{Author details}

${ }^{1}$ Institute for Experimental Medical Research and KG Jebsen Center for Cardiac Research, University of Oslo and Oslo University Hospital, Ullevål, 0027 Oslo, Norway. ${ }^{2}$ Bjørknes University College, Oslo, Norway. ${ }^{3}$ Section of Specialized Endocrinology, Department of Endocrinology, Morbid Obesity and Preventive Medicine, Medical Clinic, Oslo University Hospital, Oslo, Norway. ${ }^{4}$ Institute for Clinical Medicine, Medical Faculty, University of Oslo, Oslo, Norway. ${ }^{5}$ Department of Rheumatology, Oslo University Hospital, Rikshospitalet, Oslo, Norway. ${ }^{6}$ Department of Cardiology, Oslo University Hospital Ullevål, Oslo, Norway.

Received: 13 November 2020 Accepted: 14 April 2021

Published online: 26 April 2021

\section{References}

1. Nishimura J, Ikuyama S. Glucocorticoid-induced osteoporosis: pathogenesis and management. J Bone Miner Metab. 2000;18(6):350-2. https://doi.org/1 $0.1007 / 5007740070008$

2. Alsufyani KA, Ortiz-Alvarez O, Cabral DA, Tucker LB, Petty RE, Nadel H, et al. Bone mineral density in children and adolescents with systemic lupus erythematosus, juvenile dermatomyositis, and systemic vasculitis: relationship to disease duration, cumulative corticosteroid dose, calcium intake, and exercise. J Rheumatol. 2005;32(4):729-33.

3. Rodd C, Lang B, Ramsay T, Alos N, Huber AM, Cabral DA, et al. Incident vertebral fractures among children with rheumatic disorders 12 months after glucocorticoid initiation: a national observational study. Arthritis Care Res (Hoboken). 2012;64(1):122-31. https://doi.org/10.1002/acr.20589.

4. Elhakeem A, Frysz M, Tilling K, Tobias JH, Lawlor DA. Association between age at puberty and bone accrual from 10 to 25 years of age. JAMA Netw Open. 2019;2(8):e198918. https://doi.org/10.1001/jamanetworkopen.2019.891 8.

5. Chande S, Bergwitz C. Role of phosphate sensing in bone and mineral metabolism. Nat Rev Endocrinol. 2018;14(11):637-55. https://doi.org/10.103 8/s41574-018-0076-3.

6. Lombardi G, Di Somma C, Rubino M, Faggiano A, Vuolo L, Guerra E, et al. The roles of parathyroid hormone in bone remodeling: prospects for novel therapeutics. J Endocrinol Investig. 2011;34(7 Suppl):18-22.

7. Hardy R, Cooper MS. Bone loss in inflammatory disorders. J Endocrinol. 2009;201(3):309-20. https://doi.org/10.1677/JOE-08-0568.

8. Vasikaran S, Cooper C, Eastell R, Griesmacher A, Morris HA, Trenti T, et al. International Osteoporosis Foundation and International Federation of Clinical Chemistry and Laboratory Medicine position on bone marker standards in osteoporosis. Clin Chem Lab Med. 2011;49(8):1271-4. https:// doi.org/10.1515/CCLM.2011.602.

9. Seguro LP, Casella CB, Caparbo VF, Oliveira RM, Bonfa A, Bonfa E, et al. Lower P1NP serum levels: a predictive marker of bone loss after 1 year follow-up in premenopausal systemic lupus erythematosus patients. Osteoporos Int. 2015;26(2):459-67. https://doi.org/10.1007/s00198-014-28609.

10. Tektonidou MG, Ward MM. Validation of new biomarkers in systemic autoimmune diseases. Nat Rev Rheumatol. 2011;7(12):708-17. https://doi. org/10.1038/nrrheum.2011.157.

11. Kawazoe M, Kaneko K, Shikano K, Kusunoki N, Nanki T, Kawai S. Glucocorticoid therapy causes contradictory changes of serum Wnt signaling-related molecules in systemic autoimmune diseases. Clin Rheumatol. 2018;37(8):2169-78. https://doi.org/10.1007/s10067-017-3689-3.

12. Stewart WA, Acott PD, Salisbury SR, Lang BA. Bone mineral density in juvenile dermatomyositis: assessment using dual x-ray absorptiometry. Arthritis Rheum. 2003;48(8):2294-8. https://doi.org/10.1002/art.11211.

13. Rouster-Stevens KA, Langman CB, Price HE, Seshadri R, Shore RM, Abbott $K$, et al. RANKL:osteoprotegerin ratio and bone mineral density in children with untreated juvenile dermatomyositis. Arthritis Rheum. 2007;56(3):977-83. https://doi.org/10.1002/art.22433.

14. Castro TC, Terreri MT, Szejnfeld VL, Len C, Fonseca AS, Hilario MO. Bone mineral density of Brazilian girls with juvenile dermatomyositis. Braz J Med Biol Res. 2005;38(2):309-13. https://doi.org/10.1590/50100-879X20050002 00020.

15. Santiago RA, Silva CA, Caparbo VF, Sallum AM, Pereira RM. Bone mineral apparent density in juvenile dermatomyositis: the role of lean body mass and glucocorticoid use. Scand J Rheumatol. 2008;37(1):40-7. https://doi. org/10.1080/03009740701687226.

16. Lien G, Flato B, Haugen M, Vinje O, Sorskaar D, Dale K, et al. Frequency of osteopenia in adolescents with early-onset juvenile idiopathic arthritis: a long-term outcome study of one hundred five patients. Arthritis Rheum. 2003;48(8):2214-23. https://doi.org/10.1002/art.11097.

17. Sanner H, Gran JT, Sjaastad I, Flato B. Cumulative organ damage and prognostic factors in juvenile dermatomyositis: a cross-sectional study median 16.8 years after symptom onset. Rheumatology (Oxford). 2009; 48(12):1541-7. https://doi.org/10.1093/rheumatology/kep302.

18. Mathiesen $\mathrm{P}$, Hegaard H, Herlin T, Zak M, Pedersen FK, Nielsen S. Long-term outcome in patients with juvenile dermatomyositis: a cross-sectional followup study. Scand J Rheumatol. 2012;41(1):50-8. https://doi.org/10.3109/03 009742.2011 .608376

19. Ravelli A, Trail L, Ferrari C, Ruperto N, Pistorio A, Pilkington C, et al. Longterm outcome and prognostic factors of juvenile dermatomyositis: a multinational, multicenter study of 490 patients. Arthritis Care Res (Hoboken). 2010;62(1):63-72. https://doi.org/10.1002/acr.20015.

20. Bohan A, Peter JB. Polymyositis and dermatomyositis (first of two parts). N Engl J Med. 1975;292(7):344-7. https://doi.org/10.1056/NEJM19750213292 0706 .

21. Sanner H, Aalokken TM, Gran JT, Sjaastad I, Johansen B, Flato B. Pulmonary outcome in juvenile dermatomyositis: a case-control study. Ann Rheum Dis. 2011;70(1):86-91. https://doi.org/10.1136/ard.2010.131433.

22. Rider LG, Werth VP, Huber AM, Alexanderson H, Rao AP, Ruperto N, et al. Measures of adult and juvenile dermatomyositis, polymyositis, and inclusion body myositis: Physician and Patient/Parent Global Activity, Manual Muscle 
Testing (MMT), Health Assessment Questionnaire (HAQ)/Childhood Health Assessment Questionnaire (C-HAQ), Childhood Myositis Assessment Scale (CMAS), Myositis Disease Activity Assessment Tool (MDAAT), Disease Activity Score (DAS), Short Form 36 (SF-36), Child Health Questionnaire (CHQ), physician global damage, Myositis Damage Index (MDI), Quantitative Muscle Testing (QMT), Myositis Functional Index-2 (FI-2), Myositis Activities Profile (MAP), Inclusion Body Myositis Functional Rating Scale (IBMFRS), Cutaneous Dermatomyositis Disease Area and Severity Index (CDASI), Cutaneous Assessment Tool (CAT), Dermatomyositis Skin Severity Index (DSSI), Skindex, and Dermatology Life Quality Index (DLQI). Arthritis Care Res (Hoboken). 2011;63(Suppl 11):S118-57.

23. Sanner H, Kirkhus E, Merckoll E, Tollisen A, Roisland M, Lie BA, et al. Longterm muscular outcome and predisposing and prognostic factors in juvenile dermatomyositis: a case-control study. Arthritis Care Res (Hoboken). 2010;62(8):1103-11. https://doi.org/10.1002/acr.20203.

24. Gjesdal CG, Aanderud SJ, Haga HJ, Brun JG, Tell GS. Femoral and wholebody bone mineral density in middle-aged and older Norwegian men and women: suitability of the reference values. Osteoporos Int. 2004;15(7):52534. https://doi.org/10.1007/s00198-003-1573-2.

25. Annexstad EJ, Bollerslev J, Westvik J, Myhre AG, Godang K, Holm I, et al. The role of delayed bone age in the evaluation of stature and bone health in glucocorticoid treated patients with Duchenne muscular dystrophy. Int J Pediatr Endocrinol. 2019;2019(1):4. https://doi.org/10.1186/s13633-019-00700.

26. Lilleby V, Lien G, Frey Froslie K, Haugen M, Flato B, Forre O. Frequency of osteopenia in children and young adults with childhood-onset systemic lupus erythematosus. Arthritis Rheum. 2005;52(7):2051-9. https://doi.org/10.1 002/art.21115.

27. Compeyrot-Lacassagne S, Tyrrell PN, Atenafu E, Doria AS, Stephens D, Gilday $D$, et al. Prevalence and etiology of low bone mineral density in juvenile systemic lupus erythematosus. Arthritis Rheum. 2007;56(6):1966-73. https:// doi.org/10.1002/art.22691.

28. Holick MF, Vitamin D. Deficiency. N Engl J Med. 2007;357(3):266-81. https:// doi.org/10.1056/NEJMra070553.

29. Wienke J, Bellutti Enders F, Lim J, Mertens JS, van den Hoogen LL, Wijngaarde CA, et al. Galectin-9 and CXCL10 as biomarkers for disease activity in juvenile Dermatomyositis: a longitudinal cohort study and multicohort validation. Arthritis Rheumatol. 2019;71(8):1377-90. https://doi. org/10.1002/art.40881.

30. Rabinovich CE. Osteoporosis: a pediatric perspective. Arthritis Rheum. 2004; 50(4):1023-5. https://doi.org/10.1002/art.20129.

31. Aggarwal P, Aggarwal A, Gupta S, Misra R. Osteopenia is common in adult male patients with active juvenile idiopathic arthritis. J Rheumatol. 2006; 33(8):1642-5.

32. Munns CF, Cowell CT. Prevention and treatment of osteoporosis in chronically ill children. J Musculoskelet Neuronal Interact. 2005;5(3):262-72.

33. Lundstam K, Heck A, Mollerup C, Godang K, Baranowski M, Pernow Y, et al. Effects of parathyroidectomy versus observation on the development of vertebral fractures in mild primary hyperparathyroidism. J Clin Endocrinol Metab. 2015;100(4):1359-67. https://doi.org/10.1210/jc.2014-3441.

34. Brabnikova Maresova K, Pavelka K, Stepan JJ. Acute effects of glucocorticoids on serum markers of osteoclasts, osteoblasts, and osteocytes. Calcif Tissue Int. 2013;92(4):354-61. https://doi.org/10.1007/ s00223-012-9684-4.

35. Dong $Y$, Song $C$, Wang $Y$, Lei Z, Xu F, Guan H, et al. Inhibition of PRMT5 suppresses osteoclast differentiation and partially protects against ovariectomy-induced bone loss through downregulation of CXCL10 and RSAD2. Cell Signal. 2017;34:55-65. https://doi.org/10.1016/j.cellsig.2017.03. 004.

36. Marstein H, Schwartz T, Aalokken TM, Lund MB, Flato B, Sjaastad I, et al. Novel associations between cytokines and pulmonary involvement in juvenile dermatomyositis - a cross-sectional study of long-term disease. Rheumatology (Oxford). 2019;1862-70. https://doi.org/10.1093/rheuma tology/kez531

37. Harrison M. Erythrocyte sedimentation rate and C-reactive protein. Aust Prescr. 2015;38(3):93-4. https://doi.org/10.18773/austprescr.2015.034.

38. de Pablo P, Cooper MS, Buckley CD. Association between bone mineral density and C-reactive protein in a large population-based sample. Arthritis Rheum. 2012;64(8):2624-31. https://doi.org/10.1002/art.34474.
39. Binkley N, Ramamurthy R, Krueger D. Low vitamin D status: definition, prevalence, consequences, and correction. Rheum Dis Clin N Am. 2012; 38(1):45-59. https://doi.org/10.1016/j.rdc.2012.03.006.

40. Azali P, Barbasso Helmers S, Kockum I, Olsson T, Alfredsson L, Charles PJ, et al. Low serum levels of vitamin $D$ in idiopathic inflammatory myopathies. Ann Rheum Dis. 2013;72(4):512-6. https://doi.org/10.1136/annrheumdis-2 012-201849.

41. Robinson AB, Thierry-Palmer M, Gibson KL, Rabinovich CE. Disease activity, proteinuria, and vitamin $\mathrm{D}$ status in children with systemic lupus erythematosus and juvenile dermatomyositis. J Pediatr. 2012;160(2):297-302. https://doi.org/10.1016/j.jpeds.2011.08.011.

42. Tsaltskan V, Aldous A, Serafi S, Yakovleva A, Sami H, Mamyrova G, et al. Long-term outcomes in juvenile myositis patients. Semin Arthritis Rheum. 2020;50(1):149-55. https://doi.org/10.1016/j.semarthrit.2019.06.014.

\section{Publisher's Note}

Springer Nature remains neutral with regard to jurisdictional claims in published maps and institutional affiliations.
Ready to submit your research? Choose BMC and benefit from:

- fast, convenient online submission

- thorough peer review by experienced researchers in your field

- rapid publication on acceptance

- support for research data, including large and complex data types

- gold Open Access which fosters wider collaboration and increased citations

- maximum visibility for your research: over $100 \mathrm{M}$ website views per year

At BMC, research is always in progress.

Learn more biomedcentral.com/submissions 